\title{
Study on Leaking Characteristics of Port Plate Pair in Primary Three-Row Axial Piston Pump/Motor
}

\author{
Haishun Deng $\mathbb{D}^{\mathbb{D}}{ }^{1,2}$ Qingchun Wang $\mathbb{D}^{1},{ }^{1}$ Peng Dai, ${ }^{1}$ and Yongkang Yang ${ }^{1}$ \\ ${ }^{1}$ School of Mechanical Engineering, Anhui University of Science and Technology, Huainan, Anhui, 232001, China \\ ${ }^{2}$ Anhui Province Key Laboratory of Mine Intelligent Equipment and Technology, Huainan, Anhui, 232001, China \\ Correspondence should be addressed to Haishun Deng; dhs1998@163.com
}

Received 7 February 2018; Revised 16 July 2018; Accepted 8 August 2018; Published 16 August 2018

Academic Editor: Luis Payá

Copyright (c) 2018 Haishun Deng et al. This is an open access article distributed under the Creative Commons Attribution License, which permits unrestricted use, distribution, and reproduction in any medium, provided the original work is properly cited.

\begin{abstract}
In order to investigate the leaking characteristics of the port plate pair in primary three-row axial piston pump/motor, the present paper deducts two equations about the leakage of oil film, analyzes the effect of such parameters as oil film thickness, sealing tape width, and central angle of waist-like slot on the leakage, and arrives at the following conclusions: for the primary three-row axial piston pump/motor, the angle of heel on cylinder increases the leakage of port plat pair, but high-pressure areas on its both sides with similar displacement weaken the effect of the scope and direction of angle of heel on the leakage and help to stabilize the port plat pair's leakage and maintain the fluid lubrication; widening the sealing tape in a reasonable range can effectively bring down the leakage and raise the volume efficiency; in case of any change in the central angle of waist-like slot, the leakage of primary three-row axial piston pump/motor appears to be more stable than common type, which is more favorable for maintaining the fluid lubrication in the port plat pair. This study can shed some light on the structural design of the primary three-row axial piston pump/motor.
\end{abstract}

\section{Introduction}

Port plate pair is one of the three critical frictional pairs in axial piston pump/motor that makes use of dual waistlike slots to achieve flow assignment. During this process, leakage is inevitably caused and directly affects the volume efficiency of axial piston pump/motor. Therefore, how to control the leakage on the premise of ensuring fluid lubrication has become one of the focuses in the port plate pair related researches [1-3]. Xie Jianghui et al. [4] analyzed the ways of leakage in axial piston pump and summarized the formulas for computing the leakage of odd and even pumps. Yan Xuewen et al. [5] studied the leakage flow field along annular slot on the hydraulic plane and deducted the formula computing the slot leakage under effects of centrifugal force and differential pressure. Both of the studies examine the leakage on the basis of parallel disc models, whereas certain angle is included between the end faces of cylinder block and port plate due to the difference in the fluid oil pressure within waist-like slots on two ends of the port plate during the actual work. Deng Haishun et al. [6] suggested a new way of microfabric computing the leakage of port plate pair and analyzed the effect of cylindrical micro-pit on the leakage of port plate pair. Wang Bin et al. [7-9] created a physical leakage model of port plate pair with wedged oil film, derived the mathematical model about the leakage of port plate pair with parallel and wedged slots, and performed experimental verification.

It is made clear that the leakage of port plate pair is related to many factors such as internal structure of port plate pair, surface appearance of frictional pair $[10,11]$, rated pressure $[12,13]$, and lubricating state [14-16]. The studies above provide theoretical and experimental guideline for the design and manufacturing of port plate pair in common axial piston pump/motor. The leakage of the port plate pair in a new three-row axial piston pump/motor of axial hydraulic pressure is affected by the pressure of adjacent rows and its special structure. Moreover, the misaligned oil absorbing and pressing waist-like slots renders the pressure filed of oil film extremely complicated so that its port plate pair's leakage may differ from conventional single-row waist-like slot. Therefore, an in-depth study is needed. The primary three-row axial 


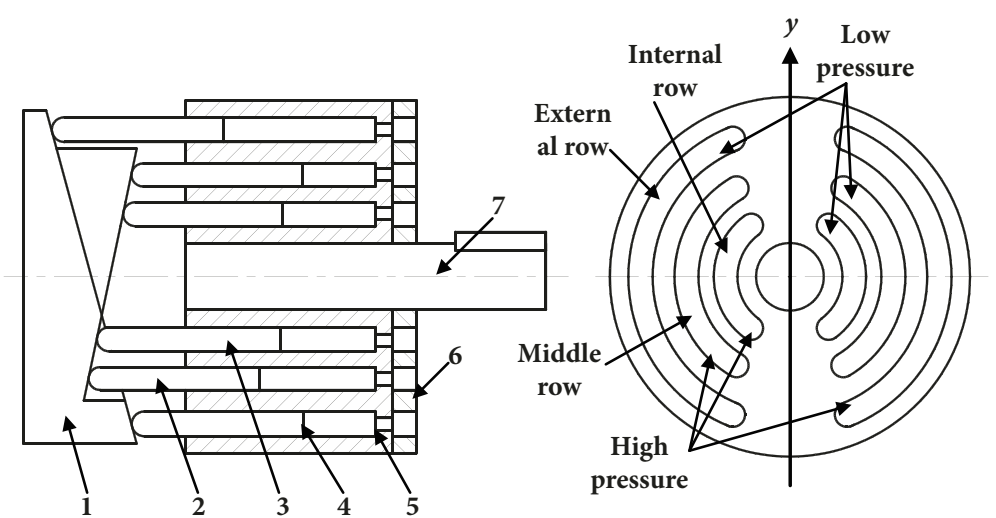

FIGURE 1: Structure of primary three-row axial piston pump/motor: 1- canted disc; (2) pistons of middle row; (3) pistons of internal row; (4) pistons of external row; (5) cylinder block; (6) port plate; (7) transmission shaft.

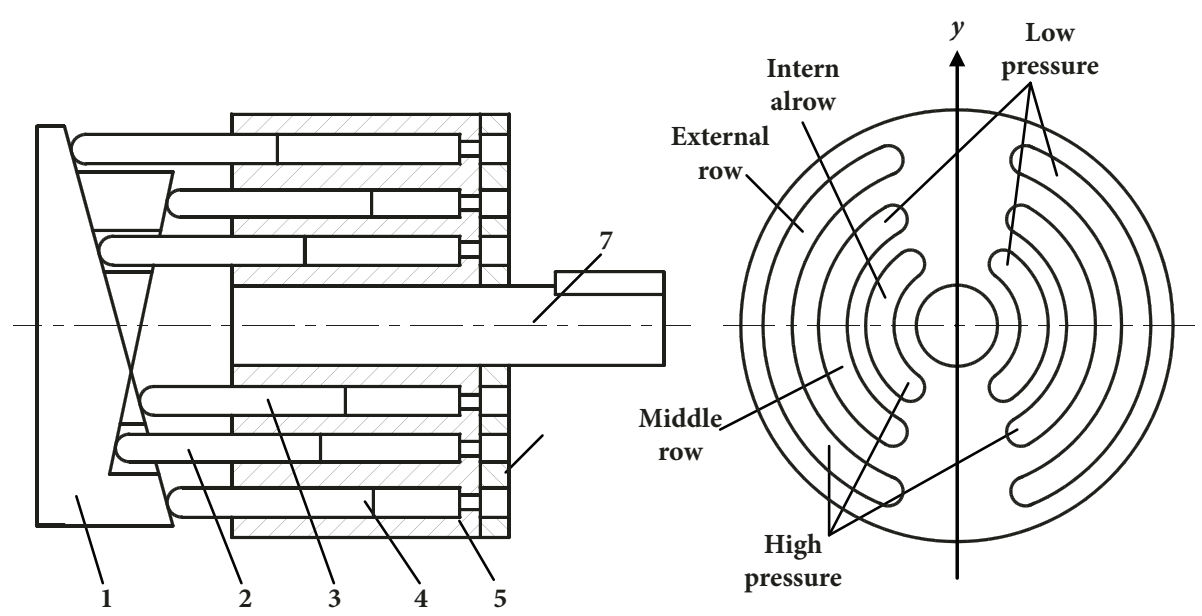

FIGURE 2: Structure of secondary three-row axial piston pump/motor: (1) canted disc; (2) pistons of middle row; (3) pistons of internal row; (4) pistons of external row; (5) cylinder block; (6) port plate; (7) transmission shaft.

piston pump/motor is an important type of the new threerow axial piston pump/motor, so the leakage of its port plate pair is studied in this paper in order to provide reference for the research about the port plate pair in the axial piston pumps/motors of similar structure.

\section{Working Principle}

The working principle of the new three-row axial piston pump/motor is as shown in Figure 1. There are several inclined planes on its canted disc, and on each of those inclined planes there is one or two rows of concentric pistons. When the axial piston pump/motor cylinder is driven by the transmission shaft to move, three rows of pistons will rotate together with the cylinder block and move back and forth along the piston hole so as to achieve simultaneous movement of internal, middle, and external rows just as in common axial piston pump/motor.

In accordance with the working principle of axial piston pump/motor, the distribution of oil inlets and outlets can be controlled through the design of canted disc's inclined plane angle. The new three-row axial port piston/pump falls into two categories as per the distribution of pistons in different rows on the inclined plane. Figure 1 demonstrates the primary three-row axial port piston/pump with its pistons of middle and internal rows located along the inclined plane angle that is opposite to the inclined plane angle of pistons of external row. Accordingly, on the port plate, the oil outlets of middle and internal rows on the left of $y$-axis have high pressure and those of external rows on the right of the $y$-axis have high pressure also.

In Figure 2, the secondary three-row axial piston pump/ motor is illustrated. Its pistons of internal and external rows are designed to have same angle of heel on the inclined plane which is opposite to that of middle rows. When it comes to the port plate, on both sides of $y$-axis, the oil ports of middle row on the left of $y$-axis have high pressure, and those of internal and external rows on the right of $y$ axis also have high pressure. In order to ensure a balanced pressure on the port plate, the oil port area of middle row can be properly widened so that the moment along $y$-axis can maintain a balance. Likewise, the oil port area of internal row can also be increased to design a tertiary structure. However, since the short arm of force for pistons of internal row is 


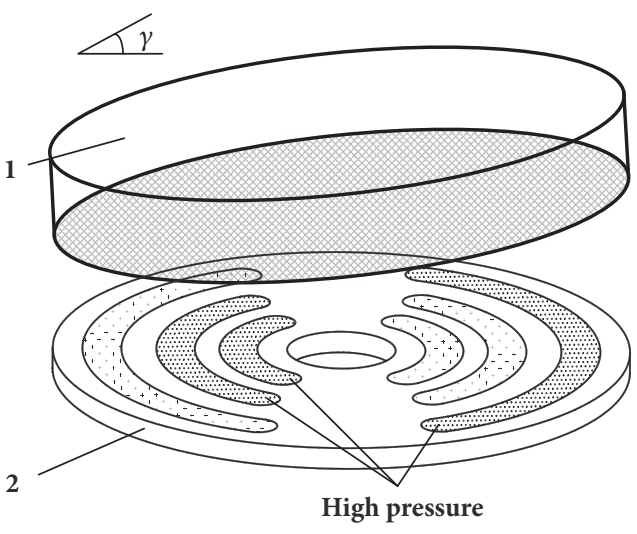

(a)

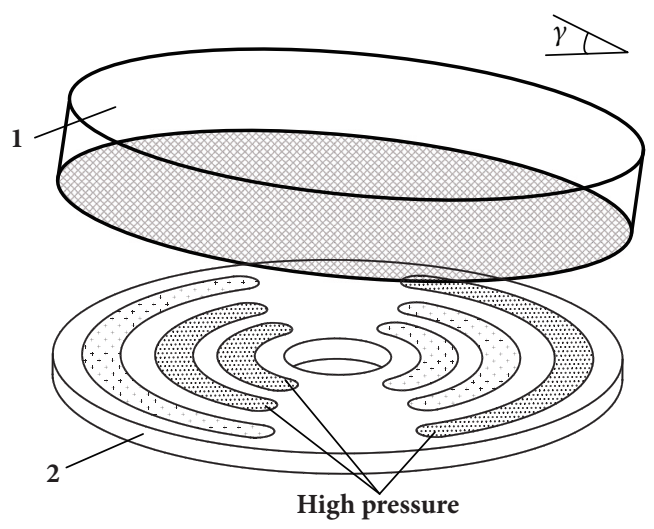

(b)

FIGURE 3: Physical model of port plate pair: (1) cylinder block and (2) port plate.

unfavorable for the balance of moment on port plate, this tertiary structure is often ruled out.

The valve plate in Figures 1 and 2 has significant differences in the high and low-pressure area of the oil ports distributed on the end face due to the different structure of the three-row axial piston pump, which results in the different direction of the upsetting moment of the end face of the cylinder relative to the end face of the valve plate and ultimately affects the overall structural design of the threerow axial piston pump.

\section{Leakage of Port Plate Pair}

For the primary three-row axial piston pump/motor, its port plate pair depends on three pairs of waist-like slots to realize oil distribution and separation of high-pressure chamber from low-pressure one during the operation. Since the port plate pair is provided with high-pressure waist-like slots on both sides, it has better stability than common axial piston pump/motor. Under the effect of spring compression force and hydraulic pressure within piston housing, the liquid oil within the sealing tape produces residual compression force. Such force is balanced with support force of oil film to achieve fluid lubrication.

Due to various reasons such as pressure fluctuation, the stress on both sides of port plate pair can be hardly balanced so that certain upsetting moment is produced [17] and an included angle $\gamma$ is formed between the end faces of cylinder block and port plate when the primary threerow axial piston pump/motor is working. As a result, the oil in high-pressure zone corresponding to the pistons of external row (hereinafter referred to as external row highpressure zone; with middle row high-pressure zone can be deduced also) is at the distal end (Figure 3(a)) or near end (Figure 3(b)) of the cylinder block's end face, while the highpressure zones of internal and middle rows are at the other end. It is, thus, necessary to compute the leakage in those two inclined situations. Figure 3 shows the physical model of primary three-row axial piston pump/motor's port plate pair in two different inclined sides.

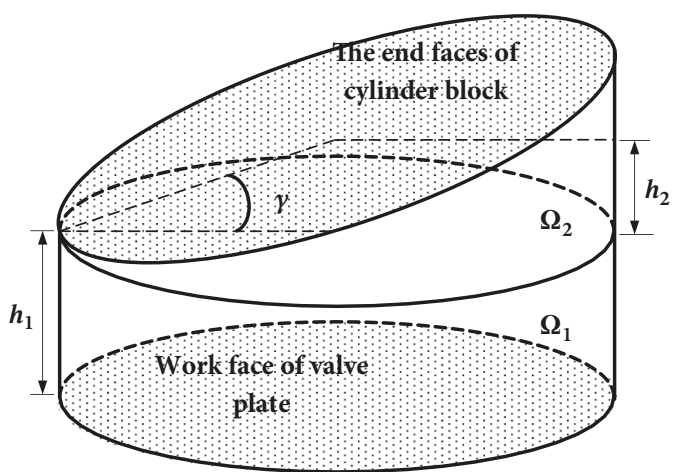

FIgURE 4: Structure division of oil film body.

In the model shown in Figure 3, such auxiliary structural elements as damper hole and V-shaped groove are omitted, and the piston hole on cylinder block is simplified to be pressure-supply area equal as the waist-like slot. The structural simplification can affect the pressure of sealing area, but not the computation of static flow [7] for the most part. Since the oil film within sealing tape is not too thick, the oil flow can be viewed as laminar flow and it is limited to the radial direction of port plate. The flow is thus symmetric to the central axis plane of the port plate. In view of the existence of cylinder block's angle of heel, the oil film of sealing tape can be deemed as being composed of the parallel oil film $\Omega_{1}$ and wedged oil film $\Omega_{2}$. The leakage of those two parts is computed separately and then added together to obtain the total leakage of the whole oil film. Figure 4 demonstrates the structure division of the oil film body.

It can be inferred that the total leakage of the oil within sealing tape of port plate pair is

$$
Q=Q_{\Omega_{1}}+Q_{\Omega_{2}}
$$

where $Q_{\Omega_{1}}$ means the leakage of the parallel oil film (unit: $\mathrm{mL} / \mathrm{min}$ ) and $Q_{\Omega_{2}}$ means that of wedged oil film (unit: $\mathrm{mL} / \mathrm{min})$. 
3.1. Leakage of Parallel Oil Film. As shown in Figure 1, for the primary three-row axial piston pump/motor, the pistons of internal and middle rows are distributed on the same canted disc plane while the pistons of external row are on the other one. The pressure distribution pattern with middle row high-pressure zone being next to the internal row highpressure zone effectively prevents the oil leakage between two high-pressure zones. In the meantime, if the pressure $p_{0}$ of middle row and internal row low-pressure zones gets ignored, the length of inward leaking channel in external row highpressure zone is extended. It is clear that when compared with common axial piston pump/motor, the primary threerow type can cut down the oil leakage with its unique port plate pair structure.

On the basis of the analysis above, the leaking routes of primary three-row axial piston pump/motor's port plate pair can be plotted (see Figure 5). The oil in external row high-pressure zone may leak into the external sealing tape of external row as well as the low-pressure zone of middle row, whereas the oil in internal row high-pressure zone can only go into the internal sealing tape of internal row, and that of middle row high-pressure zone can flow to the low-pressure zone of external row. Those are all the leaking routes of oil within the sealing tape of port plate pair. In the figure, $p_{s}$ means the working pressure of high-pressure zone in different rows and $p_{0}$ means the low-pressure zone pressure or flow channel pressure of those rows.

A cylindrical coordinate system is established with port plate plane as the basis, in which the fluid of the microgap laminal flow [18] in parallel to the wall surface is

$$
Q(r)=-\frac{\pi r}{\mu c_{\mathrm{e}}} \frac{\mathrm{d} p}{\mathrm{~d} r} \int_{0}^{h}(h-z) z \mathrm{~d} z=-\frac{\alpha h^{3} r}{12 \mu c_{\mathrm{e}}} \frac{\mathrm{d} p}{\mathrm{~d} r}
$$

For the internal sealing tape of internal row, the boundary conditions are as follows: when $r=r_{1}, p=p_{0}$ and when $r=r_{2}$, $p=p_{s}$. By solving the variables separation calculus in Formula (2), we can get the oil flow leaking from high-pressure zone of internal row to internal sealing tape of internal row as follows:

$$
Q_{\text {in }}=\left|\frac{\alpha_{1} h_{1}{ }^{3}}{12 \mu c_{\mathrm{e}}} \frac{\Delta p}{\ln \left(r_{1} / r_{2}\right)}\right|=\frac{\alpha_{1} h_{1}{ }^{3}}{12 \mu c_{\mathrm{e}}} \frac{\Delta p}{\ln \left(r_{2} / r_{1}\right)}
$$

From the waist-like slot, oil chamber of the internal row flows into the internal sealing area of the internal row, the waist-like slot oil chamber of the middle row flows into the external sealing area of the middle row (the internal sealing area of the external row), and the waist-like slot oil chamber of the external row flows into the internal sealing area of the external row (the external sealing area of the middle row) and the external sealing area of the external row, respectively, and their sum is the total leakage of the parallel oil film:

$$
\begin{aligned}
& Q_{\Omega_{1}} \\
& \quad=\frac{\Delta p h_{1}^{3}}{12 \mu c_{\mathrm{e}}}\left[\frac{\alpha_{1}}{\ln \left(r_{2} / r_{1}\right)}+\frac{2 \alpha_{2}}{\ln \left(r_{10} / r_{7}\right)}+\frac{\alpha_{3}}{\ln \left(r_{12} / r_{11}\right)}\right]
\end{aligned}
$$

where $\Delta p$ is intersealing-tape differential pressure, $\Delta p=p_{s-} p_{0}$ (unit: $\mathrm{MPa}$ ):

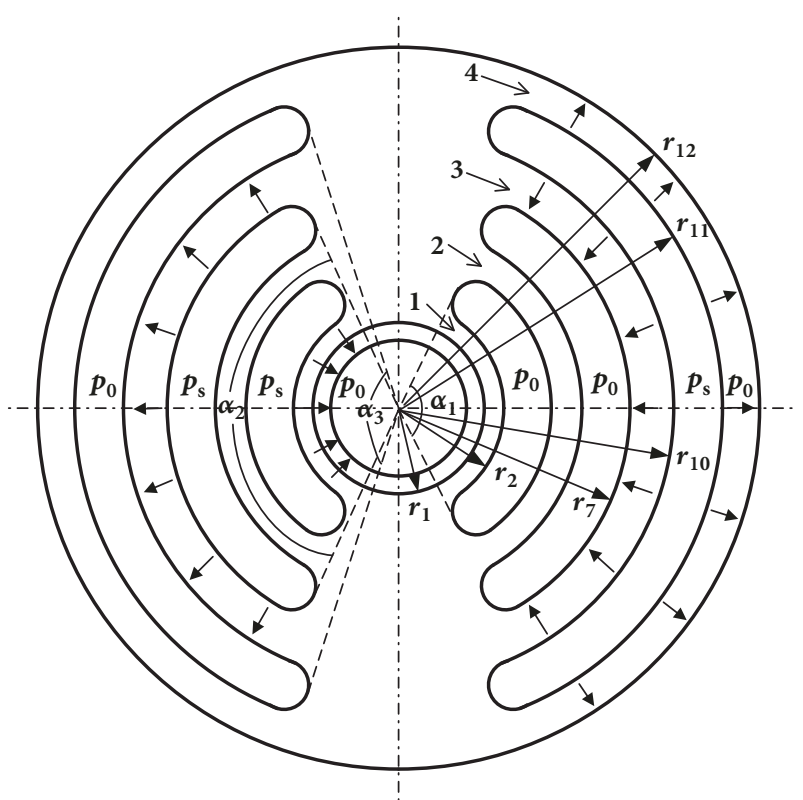

FIGURE 5: Oil leaking routes. (1)internal sealing tape of the internal row; (2) external sealing tape of the internal row (internal sealing tape of the middle row); (3) external sealing tape of the middle row (internal sealing tape of the external row); (4) external sealing tape of the external row.

$\mu$ is dynamic viscosity (unit: Pa.s);

$c_{\mathrm{e}}$ is flow correction coefficient;

$\alpha_{1}, \alpha_{2}$, and $\alpha_{3}$ are central angles of waist-like slots of internal, middle and external rows, respectively (unit: $\left.{ }^{\circ}\right)$;

$h_{1}$ is thickness of parallel oil film (unit: $\mu \mathrm{m}$ );

$r_{1}$ is inner diameter of internal row's internal sealing tape (unit: $\mathrm{mm}$ );

$r_{2}$ is outer diameter of internal row's internal sealing tape (unit: $\mathrm{mm}$ );

$r_{7}$ is inner diameter of middle row's internal sealing tape (unit: $\mathrm{mm}$ );

$r_{10}$ is outer diameter of external row's internal sealing tape (unit: $\mathrm{mm}$ );

$r_{11}$ is inner diameter of external row's external sealing tape (unit: $\mathrm{mm}$ );

$r_{12}$ is outer diameter of external row's external sealing tape (unit: $\mathrm{mm}$ ).

3.2. Leakage of Wedged Oil Film. Due to the existence of cylinder block's angle of heel, the leakage of waist-like slots on both sides of port plate should be computed separately [7]. The leakage of the waist-like slot close to the end face of cylinder block is

$$
Q_{\text {close }}(r)=-\frac{1}{6 \mu c_{\mathrm{e}}} \frac{\mathrm{d} p}{\mathrm{~d} r}\left[-r^{4} \tan ^{3} \gamma\left(\sin \frac{\alpha}{2}-\frac{1}{3} \sin ^{3} \frac{\alpha}{2}\right)\right.
$$




$$
\begin{aligned}
& +\frac{1}{2} r^{3} \tan ^{2} \gamma h_{2}(\alpha+\sin \alpha)-2 r^{2} \tan \gamma h_{2}^{2} \sin \frac{\alpha}{2} \\
& \left.+\frac{\alpha}{2} h_{2}^{3} r\right]
\end{aligned}
$$

The leakage of the waist-like slot away from the cylinder block's end face is

$$
\begin{aligned}
Q_{\mathrm{far}} & (r)=-\frac{1}{6 \mu c_{\mathrm{e}}} \frac{\mathrm{d} p}{\mathrm{~d} r}\left[r^{4} \tan ^{3} \gamma\left(\sin \frac{\alpha}{2}-\frac{1}{3} \sin ^{3} \frac{\alpha}{2}\right)\right. \\
+ & \frac{1}{2} r^{3} \tan ^{2} \gamma h_{2}(\alpha+\sin \alpha)+2 r^{2} \tan \gamma h_{2}^{2} \sin \frac{\alpha}{2} \\
+ & \left.\frac{\alpha}{2} h_{2}^{3} r\right]
\end{aligned}
$$

where $h_{2}$ is center thickness of wedged oil film (unit: $\mu \mathrm{m}$ ).

To simplify the formula, the items with insignificant order of magnitude can be omitted to obtain following formula:

$$
Q_{\text {close }}(r)=-\frac{1}{6 \mu c_{\mathrm{e}}}
$$

$$
Q_{\text {in }}=\frac{\Delta p / 6 \mu c_{\mathrm{e}}}{\left(b_{1}^{2} / a_{1}^{3}\right) \ln \left(r_{2} / r_{1}\right)-\left(b_{1}^{2} / a_{1}^{3}\right) \ln \left(\left(r_{2}-b_{1} / a_{1}\right) /\left(r_{1}-b_{1} / a_{1}\right)\right)-\left(b_{1} / a_{1}^{2}\right)\left(r_{2}^{3}-r_{1}^{3}\right)-\left(1 / 2 a_{1}\right)\left(r_{2}^{2}-r_{1}^{2}\right)}
$$

$$
\frac{\mathrm{d} p}{\mathrm{~d} r}\left[-r^{4} \tan ^{3} \gamma \sin \frac{\alpha}{2}+\frac{1}{2} r^{3} \tan ^{2} \gamma h_{2}(\alpha+\sin \alpha)\right]
$$

$$
\begin{aligned}
& Q_{\mathrm{far}}(r)=-\frac{1}{6 \mu c_{\mathrm{e}}} \\
& \cdot \frac{\mathrm{d} p}{\mathrm{~d} r}\left[r^{4} \tan ^{3} \gamma \sin \frac{\alpha}{2}+\frac{1}{2} r^{3} \tan ^{2} \gamma h_{2}(\alpha+\sin \alpha)\right]
\end{aligned}
$$

Since the inclined side of the cylinder block determines whether the wedged oil film of high-pressure zone is located at the distal or near end of the cylinder block, the leakage of the wedged oil film can be figured out according to two inclined sides of the cylinder block's end face.

When the external row's high-pressure zone is at the distal end of cylinder of cylinder block (see Figure 3(a)) internal row's high-pressure zone will be at the near end and boundary conditions of internal row's internal sealing tape will be as follows: when $r=r_{1}, p=p_{0}$ and when $r=r_{2}, p=p_{s}$. Solving the variables separation calculus in Formula (7) can derive the oil flow leaking from internal row's high-pressure zone to its internal sealing tape:
To simplify the formula, operators $a_{i}$ and $b_{i}$ are introduced, in which $i=1,2$, and 3 , indicating the internal, middle, and external rows, respectively.

$$
\begin{aligned}
& a_{i}=\frac{1}{2} \tan ^{2} \gamma h_{2}\left(\alpha_{i}+\sin \alpha_{i}\right) \\
& b_{i}=\tan ^{3} \gamma \sin \frac{\alpha_{i}}{2}
\end{aligned}
$$

From the waist-like slot, oil chamber of the internal row flows into the internal sealing area of the internal row, the

$$
\begin{aligned}
Q_{\Omega_{2}}\left(s_{1}\right)= & \frac{\Delta p / 6 \mu c_{\mathrm{e}}}{\left(b_{1}^{2} / a_{1}^{3}\right) \ln \left(r_{2} / r_{1}\right)-\left(b_{1}^{2} / a_{1}^{3}\right) \ln \left(\left(r_{2}-b_{1} / a_{1}\right) /\left(r_{1}-b_{1} / a_{1}\right)\right)-\left(b_{1} / a_{1}^{2}\right)\left(r_{2}^{3}-r_{1}^{3}\right)-\left(1 / 2 a_{1}\right)\left(r_{2}^{2}-r_{1}^{2}\right)} \\
& +\frac{\Delta p / 6 \mu c_{\mathrm{e}}}{\left(b_{2}^{2} / a_{2}^{3}\right) \ln \left(r_{10} / r_{7}\right)-\left(b_{2}^{2} / a_{2}^{3}\right) \ln \left(\left(r_{10}-b_{2} / a_{2}\right) /\left(r_{7}-b_{2} / a_{2}\right)\right)-\left(b_{2} / a_{2}^{2}\right)\left(r_{10}^{3}-r_{7}^{3}\right)-\left(1 / 2 a_{2}\right)\left(r_{10}^{2}-r_{7}^{2}\right)} \\
& +\frac{\Delta p / 6 \mu c_{\mathrm{e}}}{\left(b_{2}^{2} / a_{2}^{3}\right) \ln \left(r_{10} / r_{7}\right)-\left(b_{2}^{2} / a_{2}^{3}\right) \ln \left(\left(r_{10}+b_{2} / a_{2}\right) /\left(r_{7}+b_{2} / a_{2}\right)\right)+\left(b_{2} / a_{2}^{2}\right)\left(r_{10}^{3}-r_{7}^{3}\right)-\left(1 / 2 a_{2}\right)\left(r_{10}^{2}-r_{7}^{2}\right)} \\
& +\frac{\Delta p / 6 \mu c_{\mathrm{e}}}{\left(b_{3}^{2} / a_{3}^{3}\right) \ln \left(r_{12} / r_{11}\right)-\left(b_{3}^{2} / a_{3}^{3}\right) \ln \left(\left(r_{12}+b_{3} / a_{3}\right) /\left(r_{11}+b_{3} / a_{3}\right)\right)+\left(b_{3} / a_{3}^{2}\right)\left(r_{12}^{3}-r_{11}^{3}\right)-\left(1 / 2 a_{3}\right)\left(r_{12}^{2}-r_{11}^{2}\right)}
\end{aligned}
$$

When the external row's high-pressure zone is at the near end of the cylinder block's end face (see Figure 3), we can also waist-like slot oil chamber of the middle row flows into the external sealing area of the middle row (the internal sealing area of the external row), and the waist-like slot oil chamber of the external row flows into the internal sealing area of the external row (the external sealing area of the middle row) and the external sealing area of the external row, respectively; add in case of such inclined side:

$$
Q_{\Omega_{2}}\left(s_{2}\right)=\frac{\Delta p / 6 \mu c_{\mathrm{e}}}{\left(b_{1}^{2} / a_{1}^{3}\right) \ln \left(r_{2} / r_{1}\right)-\left(b_{1}^{2} / a_{1}^{3}\right) \ln \left(\left(r_{2}+b_{1} / a_{1}\right) /\left(r_{1}+b_{1} / a_{1}\right)\right)+\left(b_{1} / a_{1}^{2}\right)\left(r_{2}^{3}-r_{1}^{3}\right)-\left(1 / 2 a_{1}\right)\left(r_{2}^{2}-r_{1}^{2}\right)}
$$

compute the leakage of the wedged oil film in such case of inclined side: 


$$
\begin{aligned}
& +\frac{\Delta p / 6 \mu c_{\mathrm{e}}}{\left(b_{2}^{2} / a_{2}^{3}\right) \ln \left(r_{10} / r_{7}\right)-\left(b_{2}^{2} / a_{2}^{3}\right) \ln \left(\left(r_{10}-b_{2} / a_{2}\right) /\left(r_{7}-b_{2} / a_{2}\right)\right)-\left(b_{2} / a_{2}^{2}\right)\left(r_{10}^{3}-r_{7}^{3}\right)-\left(1 / 2 a_{2}\right)\left(r_{10}^{2}-r_{7}^{2}\right)} \\
& +\frac{\Delta p / 6 \mu c_{\mathrm{e}}}{\left(b_{2}^{2} / a_{2}^{3}\right) \ln \left(r_{10} / r_{7}\right)-\left(b_{2}^{2} / a_{2}^{3}\right) \ln \left(\left(r_{10}+b_{2} / a_{2}\right) /\left(r_{7}+b_{2} / a_{2}\right)\right)+\left(b_{2} / a_{2}^{2}\right)\left(r_{10}^{3}-r_{7}^{3}\right)-\left(1 / 2 a_{2}\right)\left(r_{10}^{2}-r_{7}^{2}\right)} \\
& +\frac{\Delta p / 6 \mu c_{\mathrm{e}}}{\left(b_{3}^{2} / a_{3}^{3}\right) \ln \left(r_{12} / r_{11}\right)-\left(b_{3}^{2} / a_{3}^{3}\right) \ln \left(\left(r_{12}-b_{3} / a_{3}\right) /\left(r_{11}-b_{3} / a_{3}\right)\right)-\left(b_{3} / a_{3}^{2}\right)\left(r_{12}^{3}-r_{11}^{3}\right)-\left(1 / 2 a_{3}\right)\left(r_{12}^{2}-r_{11}^{2}\right)}
\end{aligned}
$$

It can be thus inferred that the total leakage of the port plate pair in primary axial piston pump/motor is as follows:

$$
Q=\left\{\begin{array}{l}
Q_{\Omega_{1}}+Q_{\Omega_{2}}\left(s_{1}\right) \\
Q_{\Omega_{1}}+Q_{\Omega_{2}}\left(s_{2}\right)
\end{array}\right.
$$

\section{Leakage Analysis}

On the basis of the leakage equations of two kinds of oil films in port plat pair of primary three-row axial piston pump/motor, this paper further analyzes the effect of such parameters as oil film thickness, sealing tape width, and central angle of waist-like slot.

4.1. Parameters Computation. A complete set of piston pump/motor structure is designed as per the structural characteristics and methods of primary three-row axial piston pump/motor so as to determine the structural dimensions of the port plate pair. Table 1 lists the parameters involved in the leakage equations and their values. The total film thickness of the sealing tape in port plate pair is usually defined as 10$20 \mu \mathrm{m}$ [19], so the thickness $h$ of two kinds of oil films is set to be between $5 \mu \mathrm{m}$ and $10 \mathrm{um}$ in the study.

4.2. Effect of Angle of Heel on Leakage. The leakage of two kinds of oil films is figured and analyzed according to the aforesaid port plate parameters. In Figure 6, the relationship between oil film's leakage and film thickness is illustrated. From the figure, it can be found that, with thickening film, the leakage of two kinds of oil films rises, which means the oil leakage can be reduced by controlling the film thickness within a certain range so as to raise the volume efficiency of the primary three-row axial piston pump/motor. When the thickness of both oil films $h$ is $5 \mu \mathrm{m}$, the leakage of parallel oil film has a leakage $Q_{\Omega_{1}}$ of $34.7 \mathrm{~mL} / \mathrm{min}$, while that $Q_{\Omega_{2}}$ of wedged oil film is $123.2 \mathrm{~mL} / \mathrm{min}$. When $h$ is increased to 10 , the leakage $Q_{\Omega_{1}}$ of the former oil film type is $277.5 \mathrm{~mL} / \mathrm{min}$ and that $Q_{\Omega_{2}}$ of latter type is $985.7 \mathrm{~mL} / \mathrm{min}$. It is thus clear that, under same film thickness, the wedged oil film has a leakage higher than the parallel one; and with thickening film, the difference is increasingly distinct.

Therefore, the computation of port plate pair in primary three-row axial piston pump/motor should take into consideration the angle of heel of the cylinder block. Different from the port plate pair in common axial piston pump/motor, that of primary three-row type is provided with high-pressure zones on both sides to balance the upsetting moment of cylinder block to some degree. With satisfactory automatic central alignment feature, the fluctuation range of the cylinder block's angle of heel can be narrowed, which is helpful in cutting down the leakage of the port plate pair.

Figure 7 presents the film thickness-leakage curve of wedged oil film when the cylinder block inclines in two different cases. With thickening film, the leakage difference of wedged oil film also increases, but the leakage difference $\triangle Q$ of wedged oil film in two cases is no higher than $0.02 \mathrm{~mL} / \mathrm{min}$. Although it is impossible to theoretically speculate the direction of inclination of cylinder block in actual operation, its effect on the calculation of the wedged oil film's leakage is insignificant. In the design of primary three-row axial piston pump/motor, the sum of displacement of pistons of middle and internal rows is set to be equal to that of pistons of external row. As a result, when the cylinder block inclines in two different cases, the oil flows in the high-pressure zones on two sides of the port plate pair are quite close to each other, which can guarantee stable leakage of the wedged oil film so that it can better maintain the fluid lubrication capacity than that in common axial piston pump/motor.

Figure 8 analyzes the leakage of the wedged oil film under three kinds of dynamic pressure differences, which are $10 \mathrm{MPa}, 20 \mathrm{MPa}$, and $30 \mathrm{MPa}$, respectively, with amplitudes of $2 \mathrm{MPa}, 4 \mathrm{MPa}$, and $6 \mathrm{MPa}$, respectively. The thickness of oil film at the center of wedged oil film is $5 \mu \mathrm{m}$, and the amplitude is $2 \mu \mathrm{m}$. The set pressure difference fluctuation period is consistent with its flow pulsation period. The figure shows that, as the dynamic pressure difference increases, the leakage amount also increases. In the leakage fluctuation period, the maximum thickness of the film (also the maximum pressure difference of the sealing tape) corresponds to the largest amount of leakage (the corresponding peak in the fluctuation period).

4.3. Effect of Sealing Tape Width on Leakage. The sealing tape's width decides the length of oil leaking route from high-pressure zone to low-pressure one, and its effect on the leakage can by no means be ignored. The sealing tape width of the port plate in primary three-row axial piston pump/motor is closely related to the design of whole axial piston pump/motor. In comparison, the width of the internal row's internal sealing tape or external row's external sealing tape produces an insignificant effect on the overall structure of the pump/motor. Therefore, the effect of change in its width on the leakage can be studied. According to Formulas (4) and 
TABLE 1: Primary parameters of port plate pair.

\begin{tabular}{lcc}
\hline Sign and unit & Physical significance & Value \\
\hline$c_{\mathrm{e}}(-)$ & Flow correction coefficient & 2.2 \\
$h(\mu \mathrm{m})$ & Oil film thickness & - \\
$h_{1}(\mu \mathrm{m})$ & Average oil film thickness & $5 \sim 10$ \\
$h_{2}(\mu \mathrm{m})$ & Center thickness of wedged oil film & $5 \sim 10$ \\
$\Delta p(\mathrm{MPa})$ & Sealing tape's differential pressure & 30 \\
$\alpha_{1}\left({ }^{\circ}\right)$ & Central angle of internal row's waist-like slot & 130 \\
$\alpha_{2}\left(^{\circ}\right)$ & Central angle of middle row's waist-like slot \\
$\alpha_{3}\left({ }^{\circ}\right)$ & Central angle of external row's waist-like slot \\
$\Delta \alpha\left(^{\circ}\right)$ & Change amount of central angle \\
$\gamma^{\circ}\left({ }^{\circ}\right)$ & Angle of heel of cylinder block \\
$\mu(\mathrm{Pa} \cdot \mathrm{s})$ & Dynamic viscosity of oil \\
$T\left({ }^{\circ} \mathrm{C}\right)$ & Oil temperature \\
$d(\mathrm{~mm})$ & Sealing tape width \\
$r_{1}(\mathrm{~mm})$ & Inner diameter of internal row's internal sealing tape \\
$r_{2}(\mathrm{~mm})$ & Outer diameter of internal row's internal sealing tape \\
$r_{7}(\mathrm{~mm})$ & Inner diameter of middle row's internal sealing tape \\
$r_{10}(\mathrm{~mm})$ & Outer diameter of external row's internal sealing tape \\
$r_{11}(\mathrm{~mm})$ & Inner diameter of external row's external sealing tape \\
$r_{12}(\mathrm{~mm})$ & Outer diameter of external row's external sealing tape & - \\
\hline
\end{tabular}

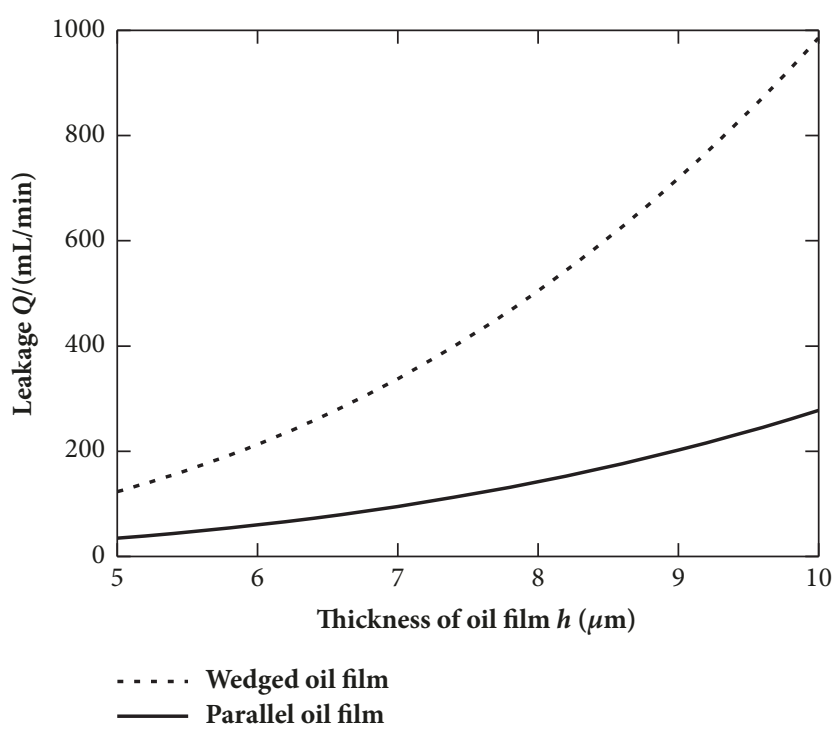

FIGURE 6: Film thickness-leakage relation of two kinds of oil films.

(12), the width of the internal sealing tape affects only the oil leakage from internal row's high-pressure zone to internal sealing tape, while that of external sealing tape only affects the oil leakage from external row's high-pressure zone to the external sealing tape. Besides, in the computation below, both the parallel oil film's thickness $h_{1}$ and the center thickness of wedged oil film $h_{2}$ are set to be $5 \mu \mathrm{m}$.

Figure 9 is a curve depicting changing leakage of two kinds of oil films from internal row's high-pressure zone to internal sealing tape with various internal sealing tape's widths; and Figure 10 presents the curve of changing leakage

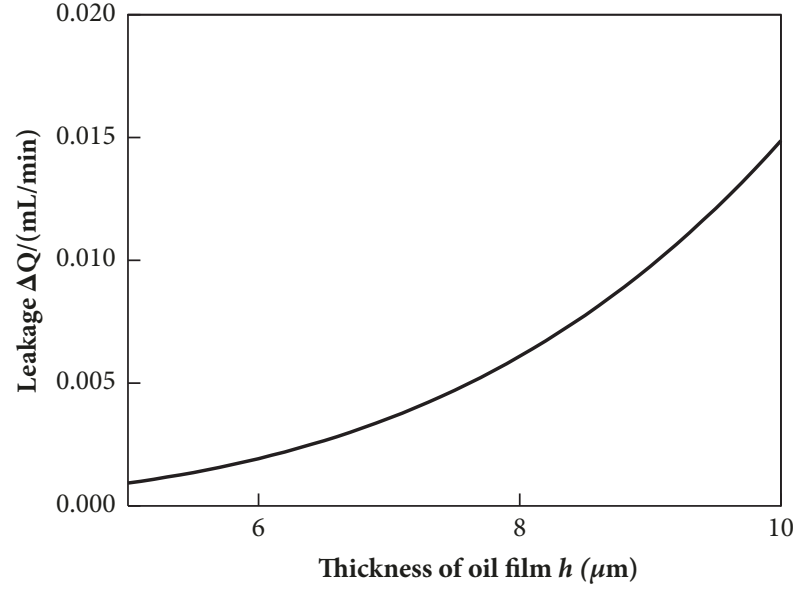

FigURE 7: Film thickness-leakage relation of wedged oil film.

from external row's high-pressure zone to external sealing tape of two oil films with various external sealing tape's widths. According to those two figures, the effects of internal and external sealing tapes' widths on their own leaking zones are quite similar to each other. When the sealing tape width $d$ is below $3 \mathrm{~mm}$, the leakage remains high; with widening sealing tape, the leakage drops; when the sealing tape width $d$ is above $6 \mathrm{~mm}$, as for the oil leaking from internal row's highpressure zone to the internal sealing tape, the leakage of the parallel oil film is lower than $5.5 \mathrm{~mL} / \mathrm{min}$ while that of wedged oil film is lower than $17.5 \mathrm{~mL} / \mathrm{min}$; and as for the oil leaking from the external row's high-pressure zone to external sealing tape, the former is below $13.5 \mathrm{~mL} / \mathrm{min}$ and the latter is below $50.8 \mathrm{~mL} / \mathrm{min}$. 


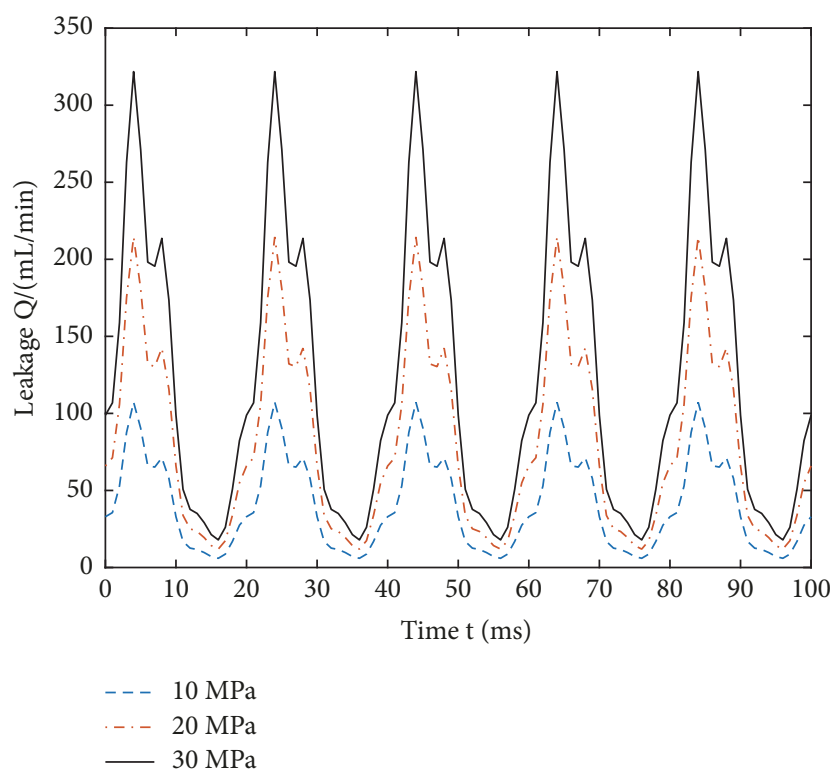

Figure 8: Relation between sealing tape pressure difference and leakage of wedged oil film.

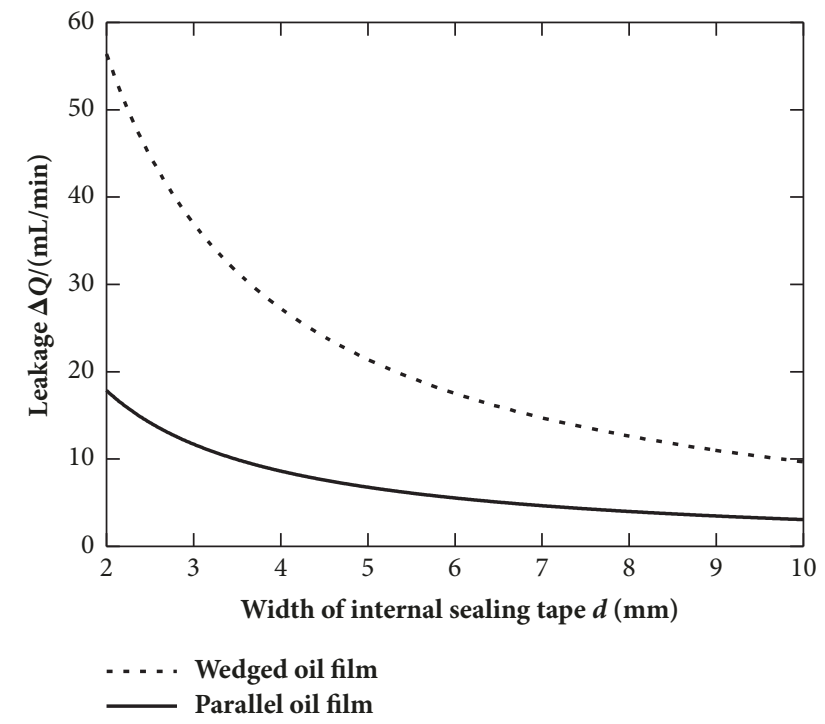

FIGURE 9: Relation between the internal sealing tape width and leakage.

In Figures 9 and 10, when the sealing tape width $d$ is over $6 \mathrm{~mm}$, the leakage curve appears to be relatively stable. At this time, the effect of sealing tape width on leakage keeps being insignificant. In the structure design of primary three-row axial piston pump/motor, overwide sealing tape may extend the diameter of cylinder block and thus affect the compactness of the piston pump/motor. Therefore, the increase of the widths of internal row's internal sealing tape and external row's external sealing tape within a reasonable range can cut down the oil leakage.

4.4. Effect of Central Angle on Leakage. The central angle of waist-like slot is linked to its displacement, which can also

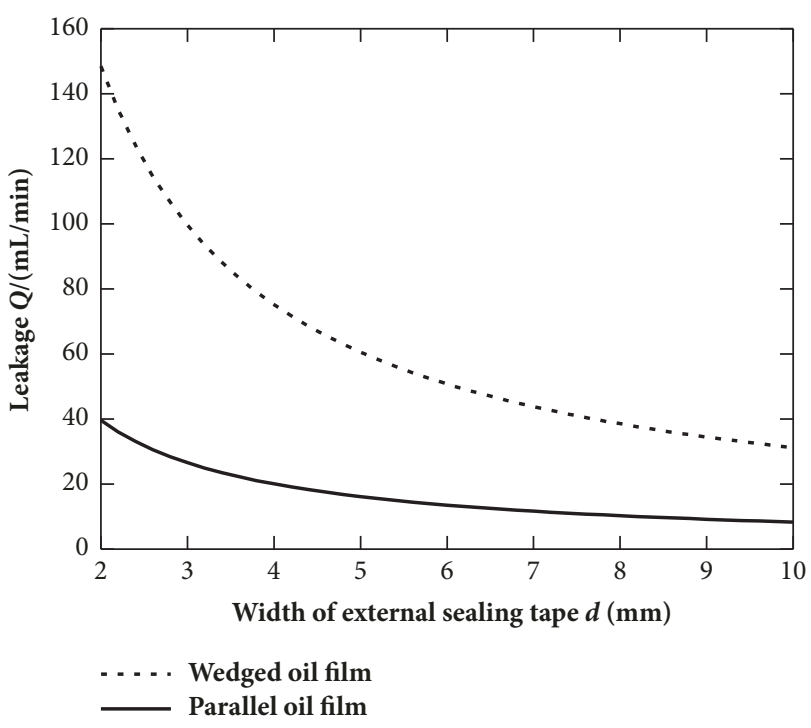

FIGURE 10: Relation between the external sealing tape width and leakage.

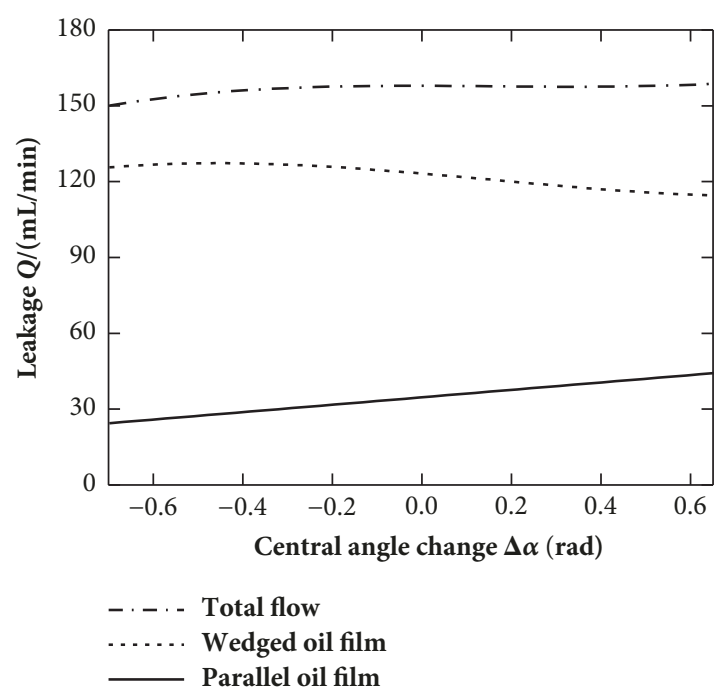

FIGURE 11: Relation between central angle change and leakage.

produce certain effect on the leakage. Figure 11 presents the curve about relation between central angle change and the leakage characteristics. In order to ensure the reliability of the leakage computation result, in computation, the effect of changing the waist-like slots of all the rows by $\Delta \alpha$ on the leakage is examined. Since the value scope of the waist-like slot's central angle is usually $[\pi / 2, \pi]$, the value scope of central angle change $\Delta \alpha$ is determined as $[2 \pi / 9, \pi / 6]$.

The leakage of common axial piston pump/motor's port plate pair rises with larger central angle of waist-like slot [7], but the primary three-row axial piston pump/motor appears to be different. Judging from the figure, we can find that, with increasing central angle, the leakage of parallel oil film also rises, but that of wedged oil film decreases slightly like that of common axial piston pump/motor. The total leakage fluctuates a little with the large change not 
exceeding $5 \%$ of the total amount. With large central angle of waist-like slot, the leakage of the common axial piston pump/motor rises accordingly, but that of primary three-row type remains stable which is favorable for maintaining stable fluid lubrication.

\section{Conclusion}

By analyzing the leaking routes of the port plate pair in primary three-row axial piston pump/motor, this paper deducts the leakage equations about two kinds of oil film, carries out corresponding computation, and draws following conclusions:

(1) The existence of the angle of heel enhances the leakage of the primary three-row axial piston pump/motor; the existence of high-pressure zones on both sides of the primary three-row axial piston pump/motor narrows the scope of the angle of heel and helps to maintain stable leakage of port plate pair and fluid lubrication; due to almost equal displacements on both sides of primary three-row axial piston pump/motor, the effect of angle of heel direction on leakage is also weakened.

(2) In case of narrow sealing tape, raising seal tape width can help to reduce the leakage of both parallel and wedged oil films; when the sealing tape width is above $6 \mathrm{~mm}$, the leakage is not significantly cut down.

(3) Different from common axial piston pump/motor, the primary three-row type has low leakage fluctuation in case of any change with its waist-like slot's central angle, which is more favorable for the port plate pair in maintaining the fluid lubrication.

\section{Data Availability}

The data used to support the findings of this study are available from the corresponding author upon request.

\section{Conflicts of Interest}

The authors declare that they have no conflicts of interest.

\section{Acknowledgments}

This paper is supported by the National Natural Science Foundation of China (Grant nos. 51575002, 51675003) and Open Foundation of the State Key Laboratory of Fluid Power and Mechatronic Systems of China (GZKF-201715)

\section{References}

[1] J. M. Bergada, S. Kumar, D. L. Davies, and J. Watton, "A complete analysis of axial piston pump leakage and output flow ripples," Applied Mathematical Modelling, vol. 36, no. 4, pp. 1731-1751, 2012.

[2] A. M. Blanco and J. M. F. Oro, "Unsteady numerical simulation of an air-operated piston pump for lubricating greases using dynamic meshes," Computers \& Fluids, vol. 57, no. 4, pp. 138150, 2012.

[3] J. Hu, Y. Zou, X. Li, and S. Lin, "Influence of elastic deformation on lubricating characteristics of port plate pair of axial piston pump," Nongye Gongcheng Xuebao, vol. 25, no. 12, pp. 114-118, 2009.

[4] J. H. Xie, J. Liu, J. Shang, D. M. Zhang, Y. Hu, and Q. S. Hu, "Analysis and calculation of leakage of swash-plate axial piston pump," Journal of Fluid Machinery, vol. 44, pp. 55-58, 70, 2016.

[5] X. W. Yan, Theoretical and experimental research on leakage characteristics of water hydraulic annular clearance, Huazhong University of Science and Technology, 2015.

[6] H. Deng, H. Yu, S. Qi, and X. Wang, "Effect of uniformly distributed micro-pits on leakage of port plate pair," Journal of Southeast University, vol. 42, no. 1, pp. 72-76, 2012.

[7] B. Wang, Lubrication characteristics and parameter optimization of plane barrel-port plate in axial piston pump, Zhejiang University, 2009.

[8] B. Wang, "Principle of Oil Film Test on Port Pair of Axial Piston Pump and Control Characteristics," Journal of Mechanical Engineering, vol. 45, no. 11, p. 113, 2009.

[9] B. Wang, H. Zhou, and H. Yang, "Real-time measurement on lubrication characteristic parameters of plane port pair in axial piston pumps," Nongye Jixie Xuebao/Transactions of the Chinese Society of Agricultural Machinery, vol. 40, no. 9, pp. 170-213, 2009.

[10] Y. Zhu, X. Chen, J. Zou, and H. Yang, "A study on the influence of surface topography on the low-speed tribological performance of port plates in axial piston pumps," Wear, vol. 338339, pp. 406-417, 2015.

[11] S. Kumar, J. M. Bergada, and J. Watton, "Axial piston pump grooved slipper analysis by CFD simulation of three-dimensional NVS equation in cylindrical coordinates," Computers \& Fluids, vol. 38, no. 3, pp. 648-663, 2009.

[12] J. M. Bergada, D. L. Davies, S. Kumar, and J. Watton, “The effect of oil pressure and temperature on barrel film thickness and barrel dynamics of an axial piston pump," Meccanica, vol. 47, no. 3, pp. 639-654, 2012.

[13] Q.-L. Ai, H. Zhou, and H.-Y. Yang, "Development and simulation of lubrication test system for port plate/cylinder block in axial piston pump," Meitan Xuebao/Journal of the China Coal Society, vol. 29, no. 6, pp. 731-735, 2004.

[14] J.-H. Shin and K.-W. Kim, "Effect of surface non-flatness on the lubrication characteristics in the valve part of a swash-plate type axial piston pump," Meccanica, vol. 49, no. 5, pp. 1275-1295, 2014.

[15] M. K. B. Khalil, J. Svoboda, and R. B. Bhat, "Modeling of Swash Plate Axial Piston Pumps With Conical Cylinder Blocks," Journal of Mechanical Design, vol. 126, no. 1, pp. 196-200, 2004.

[16] W. Zheng, Y. Xuan, and B. Lu, "Experimental Investigation into Oil Film of Valve Pair in Axial Piston Pump. Lubrication Engineering," in Lubrication Engineering, pp. 05-37, 05, 37-39, 1995.

[17] H.-S. Deng, K. Huang, C.-L. Wang, and Y.-M. Li, "Overturning moment of cylinder of balanced two-ring axial piston pump," Journal of Jilin University (Engineering and Technology Edition), vol. 45, no. 5, pp. 1468-1473, 2015.

[18] Y. M. Xu, Film theory and friction design of hydraulic pumps and motors, China Machine Press, 1987.

[19] J. Ma, B. Xu, and H. Yang, "Modeling and experiment study on fluid character of axial piston pump," Transactions of the Chinese Society for Agricultural Machinery, pp. 89-181, 2010. 


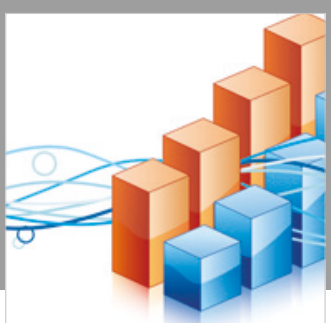

Advances in

Operations Research

\section{-n-m}
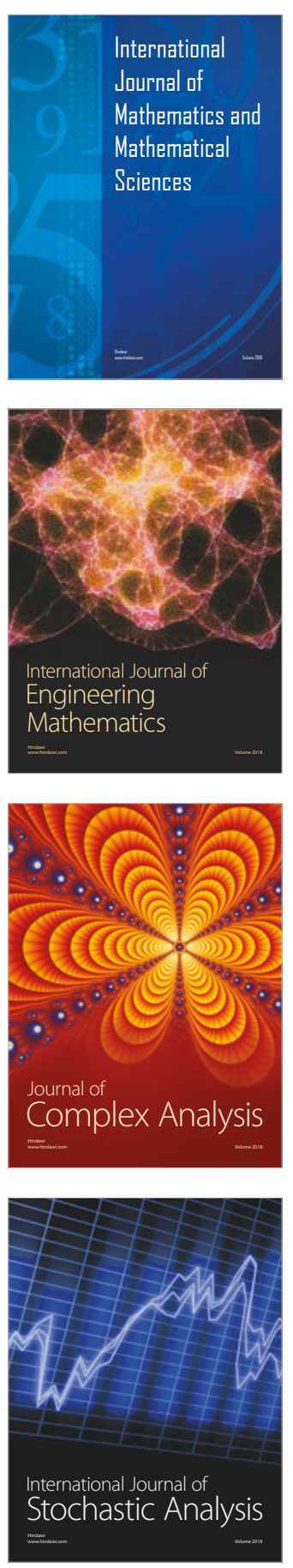
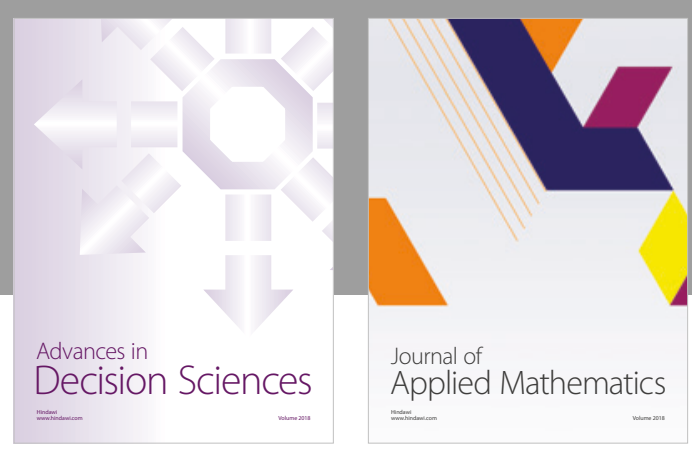

Journal of

Applied Mathematics
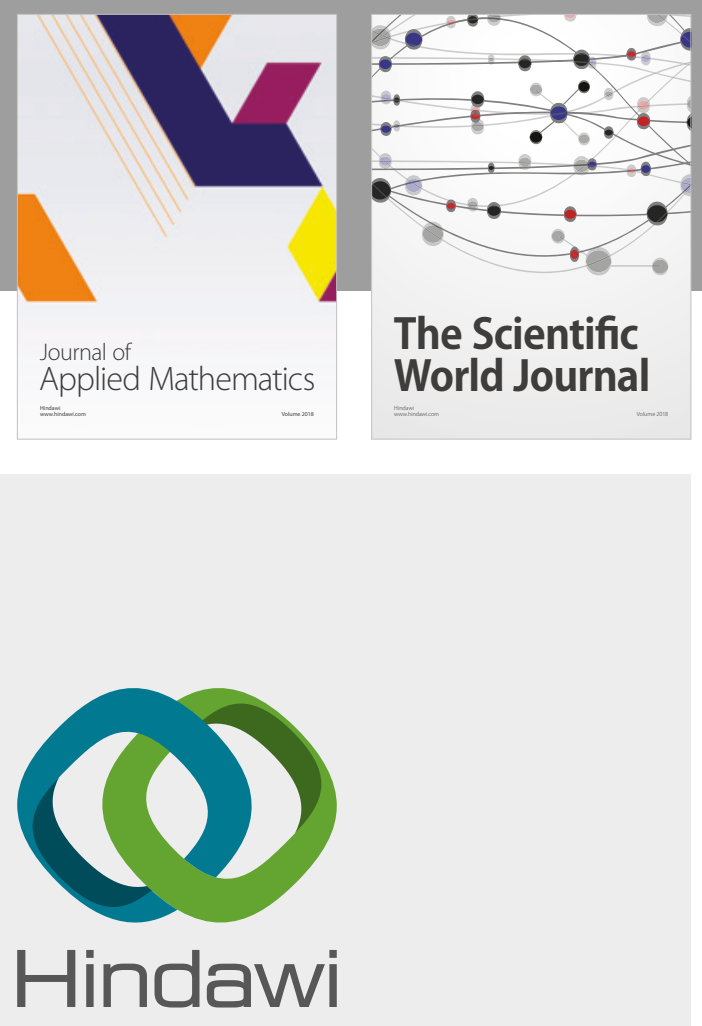

Submit your manuscripts at

www.hindawi.com

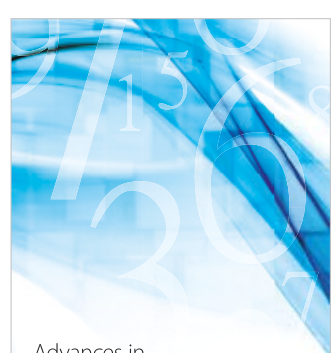

Advances in
Numerical Analysis
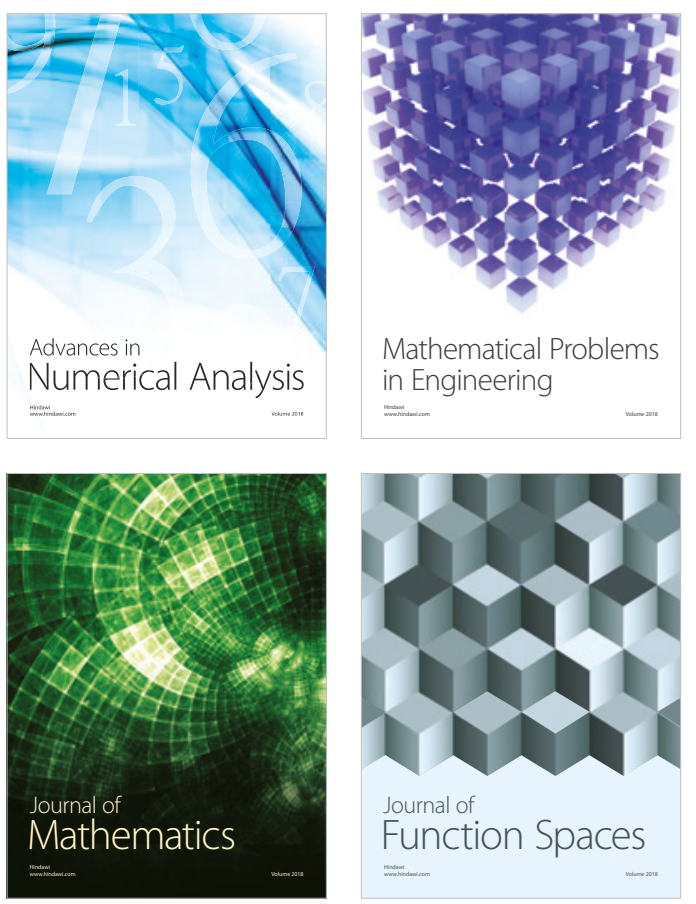

Mathematical Problems in Engineering

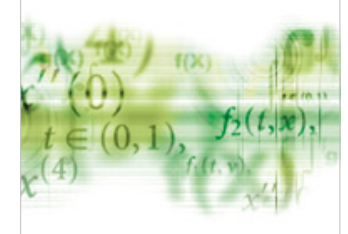

International Journal of

Differential Equations

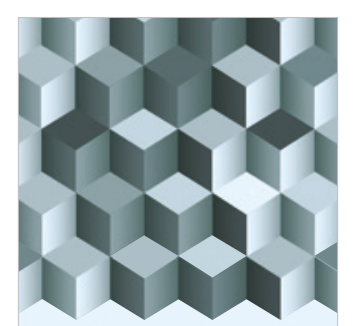

Journal of

Function Spaces

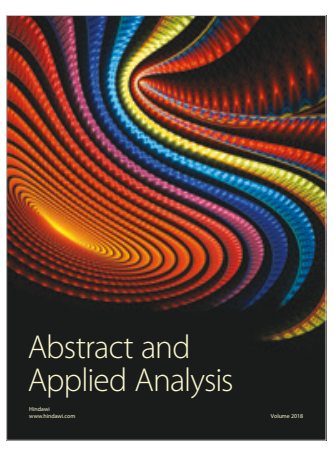

The Scientific

World Journal

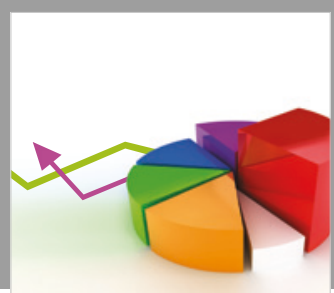

Journal of

Probability and Statistics
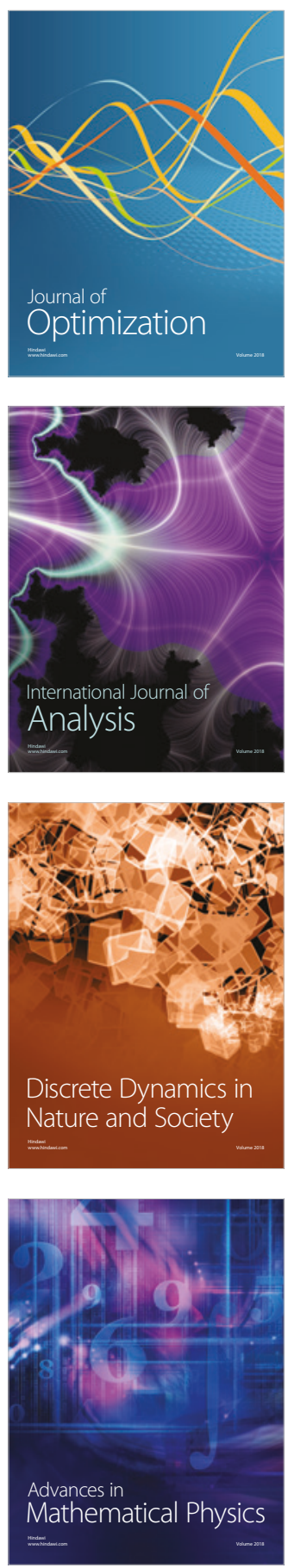